\title{
The Impact of Teaching EFL Medical Vocabulary Through Collocations on Vocabulary Retention of EFL Medical Students
}

\author{
Maryam Najafi, Mohammad Reza Talebinezhad* \\ Department of English Language Teaching, Shahreza Branch, Islamic Azad University, Shahreza, IR Iran \\ Corresponding Author: Mohammad Reza Talebinezhad, E-mail: mrezatalebinejad@gmail.com
}

\section{ARTICLE INFO}

Article history

Received: April 02, 2018

Accepted: July 06, 2018

Published: October 31, 2018

Volume: 9 Issue: 5

Advance access: August 2018

Conflicts of interest: None

Funding: None

\section{Key words:}

Vocabulary Retention,

Collocation, Teaching, EFL, ESP

\begin{abstract}
Teaching technical vocabulary in ESP context is a vital part of English language teaching at a university level. EFL teachers almost use traditional techniques for teaching new medical vocabulary. This study aimed at examining the impact of teaching medical vocabulary through collocations on vocabulary learning of medical students. This quasi-experimental study with a pretest/posttest control group design was conducted on 80 students majoring Nursing at Kashan University of Medical Sciences, Iran. The proficiency test was used to determine the proficiency level of the students and 62 students were selected as intermediate students. The students were assigned into two groups. In the experimental group new medical vocabulary was taught through collocations, while in the control group new vocabularies were instructed through traditional techniques including synonym, antonym, definition and mother tongue translation. Data were collected using a researcher-made test of collocation. Results showed that the mean score of teaching medical vocabulary was increased in the experimental group after the treatment. It can be seen that the experimental group outperformed the control group on the medical collocation tests.
\end{abstract}

\section{INTRODUCTION}

English for Specific Purposes (ESP) and general English are several branches of English language teaching. Needs analysis can be a vital asset for ESP teachers to determine their learners' key requirements or needs (Hyland, 2006). ESP is related to instruction for specific purposes, and it is associated with university level learning (Hyland \& Hamp-Lyons, 2002). Vocabulary plays the major role in the foreign language learning and without learning vocabulary learners cannot establish any communication. The basic step in mastering a foreign language is vocabulary learning. Language learning has different approaches, which have a different outlook on vocabulary (Jesa, 2008). In fact, grammar and pronunciation are considered as major components of language learning, while vocabulary is neglected in most ESP classes (Farghal \& Obiedat, 1995). A large number of scholars believed that a high level of proficiency in the target language only can be obtained by vocabulary learning (Boers \& Lindstromberg, 2008). It is believed that having a large and varied vocabulary is the sign of communicative competence and it is one of the central aspects of language learning (McCrostie, 2007). Also, vocabulary should be accepted as a key element in language teaching from the early stages (Celce-Murcia and Rosensweig, 1989). Some researchers confirm that having an adequate stock of vocabulary with a minimum number of structures usually helps the learner more not only in reading comprehension, but also in attaining more efficient communication than having a perfect command of structures with an inadequate amount of vocabulary. Also, most of the teachers prefer to use traditional vocabulary teaching techniques such as synonyms, antonyms, definition, and mother tongue translation when they want to instruct the vocabulary items. Consequently, students do not make any attempt to get to the meaning and it is unavoidable that they possibly will not remember the meaning of the new words, or even worse, they would not be able to use the new words they have learned even if they remember the meaning because they do not know the appropriate collocates. More student-centered approaches beyond behaviorism and rote memorization should be modified for the purpose of improving retention and usage (Nation, 2005). Vocabulary teaching by the use of classical techniques is considered to be too mechanical for the classroom learning. Acat (2008) declares that mechanical vocabulary learning, just memorizing new vocabulary word by word without interaction with existing knowledge, does little to improve students' vocabulary. Genç (2004) asserts that for stimulating interest and consciousness in students about vocabulary development and make the vocabulary learning process more meaningful, teachers should test different vocabulary teaching techniques.

Also, we can determine the overall proficiency of L2 learners by knowing their vocabulary knowledge. Students can enhance their listening, speaking, reading and writing abilities by learning new words. New words could be presented with collocation technique which is extremely important for acquiring vocabulary and has yet to be exploited to its full potential (Nattinger, 1988) so that students will be able to use these words later in their own performance.

Many approaches and techniques to teaching and learning vocabulary have appeared with the recognition of the importance of vocabulary, and collocation is merely one of those techniques. It is a widely accepted idea that collocations are very important part of knowledge of second language acquisition and they are essential to non-native speakers of English in order to speak or write fluently and accurately (Jaén, 2007). Skrzypek (2009) indicates the significance of collocation by asserting that one of the criteria for knowing a word is knowing other words with which it keeps company.

In today's communication era when expressing one's thoughts could lead to arising international integration, learning English has become even more essential since it serves as a medium. The demand to convey specific information has also added to this discipline. English language is the lingua franca for communicating the basic concepts of different fields, including medicine (Faraj, 2015). Medical doctors and researchers need to learn English, not only for the purpose of teaching and learning, but also for publishing their research work (Milosavljević, 2008). It has been reported that the level of medical English used in lectures, textbooks and journal articles has been increasing steadily (Hwang \& Lin, 2010). The significant role that English language 
plays in the field of medicine is due to the fact that much of the scientific, technological and academic information is globally expressed in English (Creswell, 2013). Therefore, motivating medical students and doctors to learn English is very much instrumental (Milosavljević, 2008). As was asserted previously, "English is the de facto language of international medicine" and fluency in English would be a necessity to get the essential medical and scientific information (Heming \& Nandagopal, 2012). Carrying out research and getting information are not the only factors that highlight the role of English language in medical education. The quality of medical care may be even impacted negatively by the lack of language competence (Ibrahim, 2010). Considering the significant role that English language plays in medical education, teaching medical vocabulary is worth noting more accurately. Although vocabulary has been the subject of many studies, few researchers have revealed the effective technique of teaching medical vocabulary, especially the effect of using medical vocabulary through collocations on vocabulary retention. Also, poor medical vocabulary knowledge of EFL medical students is a matter of serious concern among educational practitioners. Therefore, it seems that it would be worthwhile to explore the effect of teaching medical vocabulary through collocations in medical Iranian EFL classes.

Most of the medical students cannot use the correct medical collocations. This may result from their lack of collocational knowledge. In order to raise EFL learners' awareness of collocations and improve their accuracy in composing lexical items, the researcher asked the students to write the collocation of the highlighted words in a test and teach them the words' collocation to explore the effect of employing it on raising EFL college students' awareness of collocations.

The aim of this experiment was to answer the following research question:

1) Does presenting new medical words through collocations result in better learning of the words than presenting them using classical techniques?

\section{The Importance of Collocation in EFL Context}

Collocations, arbitrarily restricted lexeme combinations, are one type of a group of expressions whose importance in language has been increasingly recognized in recent years. This group of expressions has been variously called prefabricated units, prefabs, phraseological units, (lexical) chunks, multi-word units, or formulaic sequences.

Currently, most empirical support has come from corpus studies, which have regularly found that most of naturally occurring language, both spoken and written, consists of recurrent patterns, many of which are phraseological (e.g. Altenberg 1998; Sinclair 1991).

Several important functions have been identified for prefabricated units. First, there is growing evidence that they play an essential role in language learning, as they seem to be the basis for the development of creative language in first language and childhood second language acquisition. Secondly, prefabricated units are essential for fluency in both spoken and written language. Psycholinguistic evidence indicates that the human brain is much better equipped for memorizing than for processing, and that the availability of large numbers of prefabricated units reduces the processing effort and thus makes fluent language possible (Aitchison 2003). Thirdly, the use of prefabricated units supports comprehension, as the recipient can understand the meaning of a passage of text without having to attend to every word (Hunston \& Francis 2000). And fourthly, prefabricated units serve to indicate membership of a certain linguistic group; they fulfill "the desire to sound like others" (Wray 2002).

For the adult nonnative speaker, the first of these functions probably does not play a major role, as it seems that prefabricated language is not regularly used as a basis for creative language in adult L2 acquisition. However, two of the other functions are at least as essential for non-native speakers as for native speakers. Enhancing fluency through reducing processing effort must be of particular interest for non-native speakers, as they naturally need more processing effort to convey their intended message. Indeed, it has been shown that whether or not L2 production is fluent crucially depends on the learner's control over a large repertoire of prefabricated units (Towell \& Hawkins 1996). The third function, making comprehension easier, is doubtless of importance for every user of a language. While the use of native-like prefabs aids comprehension, non-native-like prefabs can irritate the recipient and draw the attention away from the message. The knowledge of and the ability to use prefabricated units are thus essential for the language learner. These combinations sound natural to native speakers, but students of English have to make a specific effort to learn them because they are often difficult to guess. For example, the adjective "difficult" collocates with "task", but not with "disease", so your students must be taught the collocation "severe disease".

Some collocations are fixed, or very strong, for example, "strip to the waist" but some collocations are more open, for example, "take the temperature/check the temperature.

Today, the collocational competence of medical students is paid much attention. Here are some examples of medical collocations: medical aid, premature fetus, blood test, upset stomach, admitted to hospital, prescribe treatment, adjust the dosage and many others. The collocations may refer to any kind of typical word combination, for example verb+noun (have an operation), adverb+adjective (absolutely vital), noun+noun (lack of energy), adjective+noun (streaming cold) etc.

An appreciation of collocations will help medical students to: 1) use the words they know more accurately. They will make (not do) fewer mistakes; 2) sound more natural when they speak and write. By saying, for example, "respond well to treatment", rather than "react to treatment", you won't just be understood, you will sound like a fluent user of English; 3) vary your speech, helping avoid repetitions;

We can ask our students to use, for example, the verb "prescribe" with other nouns: prescribe drugs, prescribe antibiotics etc. Or we can ask them to create their own sentences, using the new combinations, or creating short dialogues, that might include these collocations. The students should use them in different grammar forms. Collocational competence of medical students is of great importance, so, English teachers should pay it a lot of attention and they should not neglect them.

\section{Empirical Studies on Collocations}

Taylor (2000) conducted an important study on collocation. He believed that collocations are difficult to learn because joining words that are semantically compatible does not always produce acceptable combinations. Secondly, there are no standard rules that can be applied to the word combinations as word combinations differ from language to language. The knowledge of collocations requires pragmatic knowledge as well. Another reason is negative transfer from L1 and the unfamiliarity with the structure of the particular collocations. His study aimed at investigating the patterns of acquisition of English collocations and 275 junior high school Greek learners in three different levels participated in this study. He used three measures: a writing task, a gap-filling task and a translation task. The results showed that the knowledge of collocations occur gradually; the higher levels were more successful than the lower levels. Gitsaki (2000) also found that lexical collocations were more difficult to translate than grammatical collocations and the higher levels were more accurate in translating. Another finding was that the amount of exposure to a particular collocation correlated with better acquisition of that collocation. The most important conclusion of this study was that subjects were less accurate with fixed, arbitrary and unpredictable verb-noun lexical collocations. This conclusion shows that collocations are language specific and direct translation would end with inaccuracy. They should be dealt with as a significant part of vocabulary instruction. It can be inferred that lexical collocations should be taught separately, otherwise students would try to translate them, which leads them to wrong use. Nist and Simpson (1993) states that knowing the definition of a word is important and may be sufficient in many situations. However, memorizing and connecting a definition to a targeted word is just a beginning point. According to them a memorized definition is often the tip of the iceberg, the part mistakenly believed to be the total iceberg because it is so visible and obvious. Beneath the surface of the water is a much larger mass of ice which is far more important 39. Deveci (2004) states that over the last few years, vocabulary teaching has gained more interest from English teachers and theorists who argue that, without a wide range of vocabulary, grammar does not help learners much. Having a wide range of vocabulary is not adequate because a single word rarely stands alone. Therefore, language teachers need to make sure that their students know which word goes with other word(s), and that necessitates teaching collocations. Doing so will help learn- 
ers acquire the language more quickly and efficiently. Altınok (2000) conducted a study on collocation. The purpose of her study was to investigate whether teaching vocabulary in collocations will result in better vocabulary learning than teaching vocabulary using definitions only. The participants were from Cukurova University, Center of Foreign Languages Department. In the study, there were 65 students participating, one control group and two experimental groups. According to the results of her study, teaching words in collocations did not produce ant statistically significant difference in learning new vocabulary items; she still suggests that the idea that collocates of words should be taught when presenting new vocabulary because students particularly Turkish students have difficulty in finding appropriate collocates for words. The purpose of my study is to find out whether the learners learn the lexical items better in collocations rather than individually. Also, it aims to find out the extent to which the known collocates can help the students learn unknown items. This study will give a chance to gain an insight about teaching and learning collocations and compare it with teaching words in isolation.

Moreover, Aşık, Vural, and Akpınar (2016) investigated the attitudes toward data-driven learning (DDL) of 126 students in an English language teaching department. To this end, they introduced corpora or a variety of corpus tools as the content of a lexical competence course during the semester. The results indicated that lexical awareness of the students improved through DDL-based activities, in particular, improving their knowledge or "depth of vocabulary" by learning words with different collocations.

\section{METHOD}

The present study employed a quasi-experimental design making use of two groups. One group formed the experimental group and another one the control group. Pre-test/post-test design was used in this study. The pretest was administered just before presenting the collocation instruction in order to investigate the collocational comprehension of the learners and after 5 sessions of the instruction, the posttest was administered to investigate the effects of collocation instruction on learners' vocabulary retention. Finally, the scores of two tests were compared to examine the effects of the instruction. Data were analyzed using t-test by the SPSS software.

\section{Participants and Setting}

The participants in this study were 80 female students majoring nursing and operating room at Kashan University of Medical Sciences during 2016-2017. The Oxford Placement Test (OPT) was used to select the students with intermediate level of proficiency. After homogeneity of students, 62 students were selected and assigned into two groups of control $(\mathrm{n}=30)$ and experimental $(\mathrm{n}=32)$.

\section{Materials}

The words utilized in the treatment period were taken from the course book designed for the students of medicine (SAMT Publication). This book is a course for students of medicine and paramedicine who want to learn and use the English language for medical purposes. This book contains reading passages, a lucid presentation of vocabulary, and a systematic grammar syllabus in every unit. It puts particular emphasis on assisting medical students become familiar with general and technical medical vocabularies in order to use them in their courses.

\section{Procedure and Instruments}

The instrument was a 40 multiple-choice item medical collocation test (grammatical and lexical collocations) based on the collocations of their course book (SAMT Publication) to determine the vocabulary knowledge of the students. To check validity, the tests were confirmed by a couple of experienced language teachers at Kashan University. The pretest and posttest were given to a similar population. The reliability of the pretest and posttest were 0.83 and 0.79 , respectively. Then, they were administered to the participants. The subjects participated in 10 sessions of 2 hours. The 10 passages from the book were selected and given to the students during a fiveweek period (1 passage in each session).

The new vocabulary was offered to the control group via conventional techniques such as synonym, antonym, definition and mother tongue translation as it was in their routine classes before the study. The new medical vocabularies were taught to the experimental group through their collocations. The highlighted new medical vocabulary was written in a circle in the center of the board. Then, the new word's collocations were written around the word. After presenting the new words with their collocations, comprehension questions associated with the passage were asked and responded to make the task more tangible.

The same reading passages were received by the control group but no new techniques were applied to teaching the new medical vocabularies in this group. Having finished the treatment, students in both groups took the post-test to examine the effect of the treatment on vocabulary learning of the medical students.

\section{RESULTS}

In this study, 80 students majoring at nursing and operating room were voluntarily included in the study. The Oxford Placement Test (OPT) test was used to homogenize the students based on the level of proficiency. Sixty-two students were selected as intermediate students. In the treatment group 32 and in the control group 30 subjects were given the post-test. All the participants were females and given pretest before selection. The mean age of the participants was $21.3 \pm 7.4$ years. Twenty students from the treatment group and 21 from the control group were nursing students and the remainder were the operating room students. The students were most frequently from the first academic year (Table 1).

The mean score of pretest in the collocation group was $8.2 \pm 7.1$, which was increased to $17.7 \pm 11.3$ after the treatment $(\mathrm{P}<0.001)$. Also, in the control group, the mean pretest score was $8.7 \pm 6.5$, which was increased to $11.1 \pm 8.5$ after the treatment $(\mathrm{P}=0.07)$. The change in scores was 9.5 in the collocation group and 2.4 in the control group $(\mathrm{P}<0.01)$ (Table 2).

Also, analysis of covariance (ANCOVA) was used to remove the effects of pretest scores in both groups. The results of ANCOVA showed the significant effect of the treatment on the test scores by controlling the pretest effect $(\mathrm{P}<0.001)$. On the other hand, there was a significant difference in the post-test scores between the two groups $(\mathrm{P}<0.001)$.

Table 1. Distribution of demographic and educational variables in the two groups

\begin{tabular}{|c|c|c|c|c|}
\hline Variables & Control group $(n=30)$ & Treatment group $(n=32)$ & Significance & $P$ value \\
\hline Age (years) & $22.1 \pm 6.8$ & $20.9 \pm 7.8$ & $\mathrm{~T}=0.478$ & \\
\hline \multicolumn{5}{|l|}{ Academic year } \\
\hline First & 15 & 9 & & \\
\hline Second & 8 & 8 & $\mathrm{X}^{2}=0.389$ & 0.943 \\
\hline Third & 7 & 8 & & \\
\hline Fourth & 7 & 5 & & \\
\hline \multicolumn{5}{|l|}{ Field of study } \\
\hline Nursing & 20 & 21 & & \\
\hline Operating room & 12 & 9 & $X^{2}=0.598$ & 0.362 \\
\hline
\end{tabular}

$\mathrm{P}<0.01$ : level of significance 
Table 2. The mean and SD of scores in the two groups before and after the treatment

\begin{tabular}{lccl}
\hline Variable & $\begin{array}{c}\text { Treatment } \\
\text { group }\end{array}$ & $\begin{array}{c}\text { Control } \\
\text { group }\end{array}$ & P value $^{2}$ \\
\hline Score & & & \\
Before the treatment & $8.2 \pm 7.1$ & $8.7 \pm 6.5$ & $\mathrm{P}=0.07$ \\
After the treatment & $17.7 \pm 11.3$ & $11.1 \pm 8.5$ & \\
P value $^{1}$ & $\mathrm{P}<0.001$ & $\mathrm{P}<0.01$ & - \\
\hline
\end{tabular}

${ }^{1}$ Paired t-test, ${ }^{2}$ Independent t-test, $\mathrm{P}<0.01$ : level of significance

\section{DISCUSSION}

The results obtained by this experimental research revealed that teaching medical vocabulary through collocations results in a better learning of the words than presenting them using classical techniques and enhance retention of new vocabulary items. The present study's result is consistent with the result of the Özdemir (2014) study conducted on 323 Turkish medical students and it was found that a large majority of the students paid greater attention to the meaning of English words with their collocations in medicine and also students perceive learning meanings of English words with collocations as a highly important need. The result of the present study is also in line with those of the Pavičić Takač et al. (2013), which confirmed that collocations are indeed a problematic area for non-native users of medical English and teaching medical vocabulary through collocation can be very useful for these students. This study showed interesting findings regarding the impact of teaching medical vocabulary through collocations and also supported the findings of previous research studies. Research indicates that teaching medical collocation has a significant effect on vocabulary retention and instructors should strive to design course content that meets students' needs and assures optimal learning regarding. We believe that this study may be helpful for medical teachers and students in terms of becoming familiarized with a comparatively new technique which will be helpful in their vocabulary development. Based on the findings of this study, the following recommendations for additional studies, program enhancements are suggested. This study could be replicated in other technical and academic disciplines as well as other community colleges. Studies could also be conducted that address students' grammatical and lexical medical collocations separately. Similarly, Maghsodi (2010) supports our idea by stating that even though memorizing terms with their respective translations is quick and preferred by learners, it is superficial and does not let students use the needed vocabulary correctly in context. Also similar to our study, Hsu (2010) investigated the effects of direct collocation instruction on Taiwanese college English majors' reading comprehension and vocabulary learning. Similarly, the author concluded that direct collocation instruction improved the subjects' vocabulary learning and improved retention. His suggestion is in accord with our findings in that collocation instruction could be worthwhile to explore as a teaching option.

\section{CONCLUSION}

To sum up, collocation technique helped EFL medical students to remember the vocabulary items better than the classical techniques did. On the basis of this result, it could be suggested that teaching vocabulary through collocations may enhance retention of new vocabulary items in EFL classes. Also, medical students have serious problems in finding suitable collocates of words mostly because of the differences between the word order in Persian and English. We believe that this study may be helpful for medical teachers and students in terms of becoming familiarized with a comparatively new technique which will be helpful in their vocabulary development.

\section{REFERENCES}

Acat MB, (2008). Effectiveness of concept maps in vocabulary instruction. Eurasian Journal of Educational Research, 33, 1-16.

Aitchison, J. (2003). Words in the mind: An introduction to the mental lexicon (3rd ed.). Oxford: Blackwell.

Altenberg, B. (1998). "On the Phraseology of Spoken English: The Evidence of Recurrent Word-combinations”. (Ed.: Anthony P. Cowie), Phraseology, Oxford: Clarendon Press, pp. 101-122.
Altınok, Ş.İ. (2000). Teaching vocabulary using collocations versus using definitions in EFL classes.Unpublished master thesis, İhsan Doğramacı Bilkent University, Ankara.

Aşık, A., Vural, A. S., \& Akpınar, K. D. (2016). Lexical awareness and development through data driven learning: Attitudes and beliefs of EFL learners. Journal of Education and Training Studies, 4(3), 87-96.

Boers F, Lindstromberg S, (2008). How cognitive linguistics can foster effective vocabulary teaching. In: Boers F, Lindstromberg S (eds) Applications of cognitive linguistics: Cognitive linguistic Approaches to teaching vocabulary and phraseology, $1^{\text {st }}$ edn. Berlin, Mouton de Gruyter

Celce-Murcia, M., Rosensweig, F. (1989). Teaching vocabulary in the ESL classroom. In: Celce-Murcia M, McIntosh L (eds) Teaching English as a second or foreign language, $1^{\text {st }}$ edn. New York, Newbury House Publishers Inc

Creswell, J. W. (2013). Qualitative Inquiry \& Research Design Choosing Among Five Approaches-3/E

Deveci, Y. (2004). Why and How to Teach Collocations? English Teaching Forum, Vol.42, Number 2, pp 16-20.

Faraj, B. M. A. (2015). English for medical education in EFL context. Journal of Teaching English for Specific and Academic Purposes, 3(1), 121-148.

Farghal M, Obiedat H, (1995). Collocations: A neglected variable in EFL. International Review of Applied Linguistics in Language Teaching, 33(4), 315-331

Genç, B. (2004). New trends in teaching and learning vocabulary. Journal of Cukurova University Institute of Social Sciences, 13(2), 117-126

Gitsaki, C. (2000). Second language lexical acquisition: A study of the development of collocational knowledge. Maryland: International Scholars Publications.

Heming, T. A., \& Nandagopal, S. (2012). Comparative difficulties with non-scientific general vocabulary and scientific/medical terminology in English as a second language (ESL) medical students. Sultan Qaboos University medical journal, $12(4), 485$.

Hsu JT, 2010. The effects of collocation instruction on the reading comprehension and vocabulary learning of Taiwanese college English majors. The Asian EFL Journal, 12(1): 47-87.

Hunston, S., \& Francis, G. (2000). Pattern grammar: A corpus-driven approach to the lexical grammar of English. Amsterdam: John Benjamins Pub. Co.

Hwang, Y., \& Lin, S. (2010). A study of medical students' linguistic needs in Taiwan. The Asian ESP Journal, 6(1), 35-58.

Hyland, K. (2006). English for specific purposes: some influences and impacts. In A. Cummins, \& C. Davison (Eds), The International handbook of English language education (pp. 379-390), Vol 1. Norwell, Mass: Springer.

Hyland, K., \& Hamp-Lyons, L. (2002). EAP: issues and directions. Journal of English for Academic Purposes, 1(1), 1-12.

Ibrahim, A. I. (2010). ESP at the tertiary level: Current situation, application and expectation. English Language Teaching, 3(1), 200.

Jaén, MM. (2007). A corpus-driven design of a test for assessing the ESL collocational competence of university students. International Journal of English Studies, 7(2): 127-147

Jesa, M. (2008). Efficient English teaching. New Delhi: APH Publishing Corporation.

Maghsoudi M, 2010. Type of task and type of dictionary in incidental vocabulary acquisition. The Asian EFL Journal. 12(1): 8-29.

McCrostie J, 2007. Examining learner vocabulary notebooks. ELT Journal: English Language Teachers Journal. 61(3):246-255.

Milosavljević, N. (2008). Interrelationship between learning English language and students' medical education. Srpski arhiv za celokupno lekarstvo, 13(7-8), 441-444.

Nation, I.S.P. (2005). Teaching vocabulary. Asian EFL Journal. 7(3): 47-54

Nattinger JR, (1988). Some current trends in vocabulary teaching. In: Carter R, McCarty M (eds) Vocabulary and language teaching, $1^{\text {st }}$ edn. New York, Longman.

Nist, S.L., \& Simpson, M.L. (1993). Developing vocabulary concept for college thinking (1st ed.). Lexington: D. C. Heath and Company.

Özdemir, N. O. (2014). Using corpus data to teach collocations in medical English. Journal of Second Language Teaching \& Research, 3(1), $37-52$.

Pavičić, T., Višnja, E.M. (2013). "Exploring collocational competence of non-native users of medical English", JAHR, 4, 7, 235-256.

Skrzypek, A. (2009). Phonological short-term memory and L2 collocational development in adult learners. EUROSLA Yearbook, 9(1), 160-184

Sinclair, J. (1991). Corpus, concordance, collocation. Oxford: Oxford University Press.

Taylor, L. (1990). Teaching and Learning Vocabulary. London: Prentice Hall International (UK) Ltd.

Wray, A. (2002). Formulaic language and the lexicon. Cambridge: Cambridge University Pres 